\title{
REVIEW
}

\section{Role of itraconazole in haematology/oncology}

\author{
N A Pandya, A A Atra, U Riley, C R Pinkerton
}

Arch Dis Child 2003;88:258-260

The antifungal agents most frequently used in prophylaxis and treatment are amphotericin B land its new lipid forms) and azoles such as fluconazole, itraconazole, and more recently voriconazole. This review assesses the role of itraconazole in paediatric haematology/oncology practice. Its broader spectrum of activity and availability in oral and intravenous forms allow a flexible approach in the management of fungal infections.

See end of article for authors' affiliations

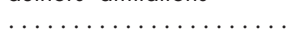

Correspondence to:

Professor C R Pinkerton,

Institute of Cancer

Research, The Royal

Marsden Hospital, Downs

Road, Sutton, Surrey

SM2 5PT, UK;

rossp@icr.ac.uk

Accepted 27 August 2002

.................. nvasive fungal infections (IFI) are a major cause of morbidity and mortality among neutropenic cancer patients. Their incidence has increased over the past decade because of increasing intensity of chemotherapy regimens and the use of high dose therapy with stem cell rescue. ${ }^{12}$ In Europe and North America, candida and aspergillus infections are the most common. The diagnosis of IFI remains elusive and challenging and contrary to the case with bacterial infections, therapeutic intervention has limited success. As a result, prophylaxis and empirical pre-emptive therapy play a key role in patient management. ${ }^{3-5}$

\section{PHARMACOLOGY AND PHARMACOKINETICS}

Itraconazole is highly lipophilic and is tightly bound to blood cells and plasma proteins, primarily albumin, leaving only $0.2 \%$ unbound. ${ }^{6} \mathrm{Be}-$ cause of its lipophilic nature, it is extensively distributed in tissues such as liver, lung, and bone where its concentration is $2-3$ times higher than in serum. ${ }^{7}$ It is metabolised primarily in the liver, and the single dose pharmacokinetics are not affected by renal dysfunction. ${ }^{8}$ The erratic absorption and reduced bioavailability of the capsule form has been overcome with the introduction of a liquid formulation in cyclodextrin. The bioavailability of itraconazole oral solution is $60 \%$ higher than that of capsules. ${ }^{9-11}$ The absorption of the liquid formulation is enhanced if given under fasting conditions and is not affected by reduced gastric acidity in contrast to the capsule preparation. The capsule formulation requires food for dissolution of the drug from the solid formulation. The capsule preparation has a reduced bioavailability in a fasted state than when administered with food. The oral solution itraconazole is delivered into the stomach already adequately dissolved for maximum absorption.

Because the solution does not require the intake of food, it is an important alternative for patients with reduced oral intake, hypoacidity, mucositis, or inability to swallow oral capsules. Use of acidic beverage (cola) aids in absorption of itraconazole capsule formation. ${ }^{12-14}$

Pharmacokinetic studies in children have shown that plasma levels (measured by HPLC) higher than $250 \mathrm{ng} / \mathrm{ml}$ (necessary for effective prophylaxis) may be achieved after three days in 6-14 year old children, and after five days in children under 5 who received $5 \mathrm{mg} / \mathrm{kg} /$ day of itraconazole oral solution. ${ }^{15}{ }^{16}$ In the majority of patients a steady state plasma level is reached after two weeks of itraconazole oral solution at a dose of 5 $\mathrm{mg} / \mathrm{kg}$ daily. ${ }^{11}$ High concentrations have been detected in saliva for about eight hours after single dose of itraconazole oral solution. ${ }^{17}$

In patients at high risk of IFI, such as those post-allogeneic stem cell transplantation procedures, who have severe mucositis or graft versus host disease (GVHD), manifesting as a wide range of upper gastrointestinal abnormalities, oral administration may be difficult and absorption may be reduced. ${ }^{18}{ }^{19}$ Frequent vomiting or difficulty in swallowing can further hamper absorption and the achievement adequate levels of drug. Antacids may reduce absorption of itraconazole capsule formulation.

Intravenous itraconazole is now available and has helped to overcome these problems; it achieves steady state plasma concentrations in 48-96 hours. ${ }^{20}$

Itraconazole can inhibit the metabolism of drugs used in oncology practice such as warfarin, cyclosporin A, clarythromycin, tacrolimus, and busulphan, resulting in reduced clearance and prolongation of the effects of these drugs. ${ }^{21}{ }^{22}$ Itraconazole metabolism is increased by carbamazepine, phenytoin, and rifampicin. The combination of itraconazole and vincristine may exacerbate the neurotoxicity of the latter. ${ }^{23}$

\section{MECHANISM OF ACTION}

Itraconazole is a broad spectrum triazole antifungal agent with three nitrogen atoms, resulting in an increased affinity to, and ultimately inhibition of, fungal cytochrome P450. Fluconazole similarly has three nitrogen atoms, but has a hydrophilic side chain. The inhibition of cytochrome P450 prevents the synthesis of ergosterol, a vital component of the fungal cell membrane. Itraconazole's main metabolite, hydroxyitraconazole, reaches higher plasma concentrations than the parent compound and has in vitro antifungal activity similar to that of itraconazole. ${ }^{24}$

Abbreviations: GVHD, graft versus host disease; IFI, invasive fungal infections 


\section{ADVERSE EFFECTS}

A recent study in children showed that itraconazole oral solution is generally well tolerated and safe. Some patients experienced diarrhoea secondary to cyclodextrin. Other common minor side effects include constipation, abdominal pain, nausea, and headache. ${ }^{25}$ Increases in serum alanine aminotransferase (ALT) have been observed..$^{12}$ Compliance may be a problem because of the taste of itraconazole. ${ }^{26}$

\section{PROPHYLACTIC USE}

The mortality rate of IFI remains very high, despite the availability of many antifungal agents. This has led to the use of pre-emptive therapy in patients at high risk of IFI, such as those with severe prolonged neutropenia and/or impaired cellular immunity. Patients with GVHD on immunosuppressive therapy following allogeneic stem cell transplantation, particularly after mismatched or unrelated transplant, are at particular risk. ${ }^{27}{ }^{28}$ The most common fungal infections in cancer patients are candida and aspergillus species. ${ }^{29}$ Itraconazole is effective against both and would seem an ideal drug for prophylaxis. A recent non-randomised study in children undergoing intensive chemotherapy with or without stem cell rescue suggested that itraconazole $2.5 \mathrm{mg} / \mathrm{kg}$ twice daily (median duration of prophylaxis 37 days) was safe and could be used for prophylaxis in high risk children. ${ }^{25}$ Randomised trials comparing itraconazole with fluconazole, amphotercin $\mathrm{B}$, or placebo showed that the former is well tolerated and might decrease the incidence of fungal infection in cancer patients. $^{3031}$ As with other azoles, emergence of itraconazole resistant candida and aspergillus has been reported, particularly following prolonged use. ${ }^{32}$

\section{ITRACONAZOLE IN THE TREATMENT OF PRESUMED OR PROBABLE FUNGAL INFECTION}

Itraconazole, with its safety and broad spectrum activity against both aspergillus and candida, is a good alternative to amphotericin B. Other possible indications include:

- Allergic reaction to amphotericin or liposomal amphotericin, or increased potassium requirements

- Deteriorating renal function

- Candidiasis resistant to fluconazole treatment

- Proven systemic aspergillosis.

The usual dose schedule is $2.5 \mathrm{mg} / \mathrm{kg}$ intravenously twice daily for the first two days to achieve a good plasma concentration followed by once daily dose for the duration of treatment. Oral itraconazole $5 \mathrm{mg} / \mathrm{kg} /$ day may be used as an outpatient if a prolonged treatment is required. Blood levels have been recommended in patients on oral therapy or with documented fungal infections to ensure a satisfactory plasma level is achieved..$^{15} 16$

Prospective economic analysis of intravenous itraconazole compared to conventional and liposome amphotericin B was conducted in six European countries to evaluate the cost and cost effectiveness of intravenous itraconazole in patients with presumed IFI. It was concluded that itraconazole might be a cost effective option compared to other agents. At a daily cost of $€ 103$ per $200 \mathrm{mg}$, itraconazole produced savings compared with conventional amphotericin B in Germany, UK, Italy, and Sweden, ranging from €629 to €2201 per patient. ${ }^{33}$

\section{CONCLUSION}

Intravenous amphotericin B remains the gold standard treatment of IFI, with the liposomal preparation used in proven infection or to avoid renal toxicity. Itraconazole, in all its formulations, has proven record of successful treatment of IFIs. It is better tolerated than amphotericin and cheaper than liposomal amphotericin. Antifungal prophylaxis using itraconazole oral solution may reduce fungal infections in neutropenic patients with haematological malignancies, and has the potential to prevent reactivation of fungal infection in patients with previous fungal infection. There is a need for randomised studies in children to clarify the indications for this drug in haematology practice.

\section{Authors' affiliations}

N A Pandya, A A Atra, C R Pinkerton, Department of Paediatric Oncology, The Royal Marsden Hospital NHS Trust, Institute of Cancer Research, Sutton, Surrey SM2 5PT, UK

U Riley, Department of Microbiology, The Royal Marsden Hospital NHS Trust

\section{REFERENCES}

1 Bodey GP. Infections in cancer patients, a continuing association. Am J Med 1986;81:11-26

2 Nucci M, Biasoli I, Tiyomi A, et al. A double blind, randomised, placebo-controlled trial of itraconazole prophylaxis for neutropenic patients. Clin Infect Dis 2000;30:300-5.

3 Pizzo PA, Rubin M, Freifeld A, et al. The child with cancer and infection II. Nonbacterial infections. J Pediatr 1991;119:845-85.

4 Prentice HG, Caillot D, Dupont B, et al. Oral and intravenous itraconazole for systemic fungal infections in neutropenic haematological patients. Acta Haematol 1999;101:56-62.

5 Gozdasoglu S, Ertem M, Buyukkececi Z, et al. Fungal colonisation and infection in children with acute leukaemia and lymphoma during induction therapy. Med Paediatr Oncol 1999;32:344-8.

6 Grant SM, Clissold SP. Itraconazole. A review of its pharmacodynamic and pharmacokinetic properties, and therapeutic use in superficial and systemic mycoses. Drugs 1989;37:310-44.

7 De Beule K, Heykants J, Van Cutsem J, et al. Clinical relevance of in vitro sensitivity in relation to tissue levels of itraconazole in internal organs. 11 th Congress of the International Society for Human and Animal Mycology, Montreal, Canada, 24-28 June 1991, Montreal, Canada/17th International Congress of Chemotherapy, Berlin, Germany, 23-28 June 1991. 1991:132.

8 Boelaert J, Schurgers M, Matthys R, et al. Itraconazole pharmacokinetics in patients with renal dysfunction. Antimicrob Agents Chemother 1988;32:1595-7

9 Barone JA, Moskovitz BL, Guarnieri J, et al. Enhanced bioavailability of itraconazole in hydroxy-propyl b cyclodextrin solution versus capsules in healthy volunteers. Antimicrob Agents Chemother 1998:42:1862-5.

10 Van de Velde VJS, Van Peer AP, Heykants JJP, et al. Effect of food on the pharmacokinetics of a new hydroxy-propyl beta cyclodextrin formulation of itraconazole. Pharmacotherapy 1996;16:424-8.

11 Repentigny de Louis, Ratelle J, Leclerc J-M, et al. Repeated-dose pharmacokinetics of an oral solution of itraconazole in infants and children. Antimicrob Agents Chemother 1998;42:404-8.

12 Barone JA, Moskovitz BL, Guarnieri J, et al. Food interaction and steady state pharmacokinetics of itraconazole solution in healthy volunteers. Pharmacotherapy 1998;18:295-301.

13 Van Peer A, Woestenborghs R, Heykants J, et al. The effects of food and dose on the oral systemic availability of itraconazole in healthy subjects. Eur J Clin Pharmacol 1989;36:423-6.

14 Jaruratanasirikul S, Kleepkaew A. Influence of an acidic beverage (Coca-cola) on the absorption of itraconazole: Eur J Clin Pharmacol 1997:52:235-7.

15 Boogaerts MA, Verhoef GE, Zachee P, et al. Antifungal prophylaxis with itraconazole in prolonged neutropenia: correlation with plasma levels. Mycoses 1989;32:103-8.

16 Levron JC, Chwetzoff E, Lapparareau Gallot, et al. Pharmacokinetic study of itraconazole oral solution during chronic treatment in neutropenic children. Beerse: Janssen Research Foundation, 1997.

17 Reynes J, Bazin C, Ajana F, et al. Pharmacokinetics of itraconazole solution in two groups of human immunodeficiency virus infected adults with oral candidiaisis. Antimicrob Agents Chemother 1997:41:2554-8.

18 Bradford CR, Prentice AG, Warnock DW, et al. Comparison of the multiple dose pharmacokinetics of two formulations of itraconazole during remission induction for acute AML. Antimicrob Agents Chemother 1991;28:555-60.

19 Persat F, Marzullo D, Guyotat M, et al. Plasma itraconazole concentrations in neutropenic patients after repeated high dose treatment. Eur J Cancer 1992;28:838-41

20 Vandewoude K, Vogalaers J, Decruyenaere P, et al. Concentrations in plasma and safety of 7 days of intravenous itraconazole followed by 2 weeks of oral itraconazole solution in patients in intensive care units. Antimicrob Agents Chemother 1997;41:2714-18.

21 Buggia I, Zecca M, Alessandrino EP, et al. Itraconazole can increase systemic exposure to busulphan in patients given BMT (GITMO). Anticancer Res 1996;16:2083-8.

22 van't Wout JW. Therapeutic indications for new triazoles and potential emergence of resistance. Baillieres Clin Infect Dis 1995;12:111-23. 
23 Bohme A, GanserA, Hoelzer A. Aggravation of vincristine induced neurotoxicity by itraconazole in the treatment of adult ALL. Ann Haematol 1995;71:311-12.

24 Beule De Karen, Gestel Jef Van. Pharmacology of itraconazole. Drugs 2001;61(suppl 1):27-37.

25 Foot AB, Veys PA, Gibson BE. Itraconazole oral solution as antifungal prophylaxis in children undergoing stem cell transplantation or intensive chemotherapy for haematological disorders. Bone Marrow Transplant 1999;24:1089-93

26 Morgenstern GR, Prentice AG, Prentice HG, et al. A randomised controlled trial of itraconazole versus fluconazole for the prevention of fungal infections in patients with haematological malignancy. $\mathrm{BrJ}$ Haematol 1999; 105:901-11.

27 Meyers JD. Fungal infections in bone marrow transplant patients. Semin Oncol 1990;17:10-13.

28 Walter EA, Bowden RA. Infection in bone marrow transplant recipient. Infect Dis North Am 1995;9:823-47.
29 Jantunen E, Ruutu P, Niskanen L, et al. Incidence and risk factors for invasive fungal infections in allogenic BMT recipients. Bone Marrow Transplant 1997;19:801-8.

30 Heykants J, Van Peer A. The clinical pharmacokinetics of itraconazole: an overview. Mycoses 1989;32(supp 1):67-87.

31 Harousseau J, Dekker A, Stamtoullas-Bastard A, et al. Itraconazole oral solution for primary prophylaxis of fungal infections in patients with haematological malignancy and profound neutropenia: a randomised, double blind, double placebo, multicenter trial comparing itraconazole and amphotericin B. Antimicrob Agents Chemother 2000:44:1887-93.

32 Denning DW, Venkateswarlu K, Oakley KL, et al. Itraconazole resistance in Aspergillus fumigatus. Antimicrob Agents Chemother 1997;41:1364-8.

33 Annemans L. Economic evaluation of itraconazole in presumed systemic fungal infections: a multicountry ANALYSIS. Proceedings of the 3rd International Symposium, Optimising Management Strategies for Systemic Fungal Infections, Oporto, Portugal, 22-24 April 1999

\section{IMAGES IN PAEDIATRICS}

\section{Craniosynostosis due to premature closing of the sagittal suture}

A 7 month old boy was admitted to our paediatric department with a fever up to $40^{\circ} \mathrm{C}$ and diarrhoea. Physical examination revealed closed anterior fontanelle, scaphocephaly (long and narrow skull) (fig 1), frontal bossing, and two hair whorls. Head circumference was $47.5 \mathrm{~cm}$ (above 97\%). Previous records of head circumference showed continuous growth on the same percentile. His neurological examination was normal as well as his development. A CT scan with $3 \mathrm{D}$ construction (fig $2 \mathrm{~A}$ and $\mathrm{B}$ ) revealed early closure of the sagittal suture.

Craniosynostosis is defined as premature closure of the cranial sutures. The incidence of primary craniosynostosis is $1 / 2000$ births. Scaphocephaly is sporadic and more common in males and may cause difficulties during labour. Scaphocephaly does not produce increased intracranial pressure or hydrocephalus, and neurological examination results of affected patients are normal.

R Shaoul

Departments of Pediatrics Bnai Zion Medical Center, Faculty of Medicine, Technion, Haifa, Israel; shaoul_r@netvision.net.il

A Toubi
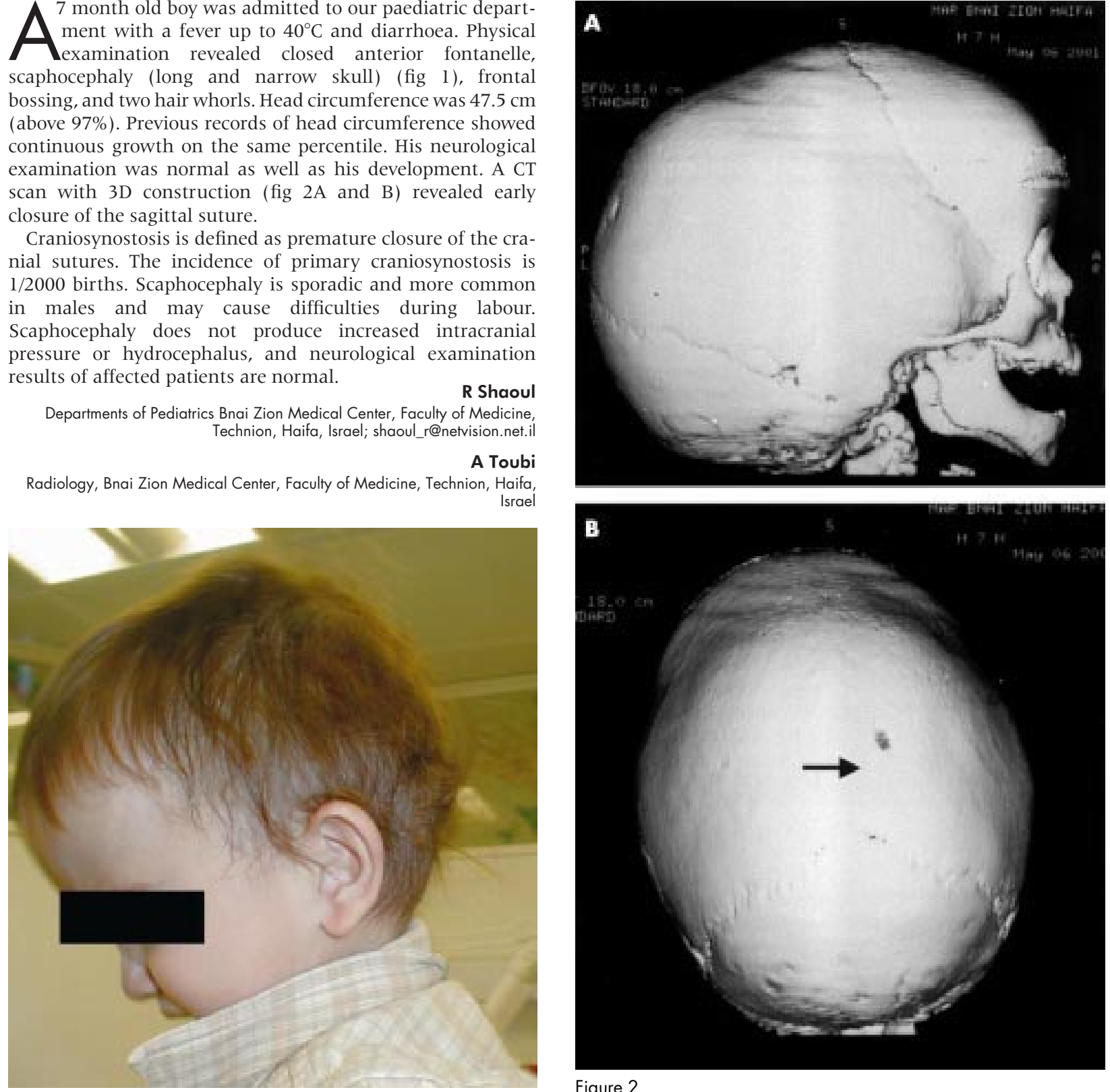

Figure 2

Figure 1 